\title{
Association between Obesity and
} Neighborhood Socioeconomic Status in Korean Adolescents Based on the 2013 Korea Youth Risk Behavior Web-Based Survey

\author{
Sung Won Choi, Da-jung Park*, Jinseung Kim*, Tae-jin Park, Jun-su Kim, Sunghun Byun, Young-seok Lee, \\ Jung-hoon Kim \\ Department of Family Medicine, Inje University Busan Paik Hospital, Inje University College of Medicine, Busan, Korea
}

\begin{abstract}
Background: An increase in the obese adolescent population is being recognized as a serious medical and social problem. The present study aimed to examine the association between neighborhood socioeconomic status (SES) and obesity in Korean adolescents based on total available resources and local social inequality models.

Methods: The present study used data from the 2013 Korea Youth Risk Behavior Web-based Survey in analyzing 72,438 Korean adolescents aged 12-18. The analysis investigated obesity odds ratio (OR) according to neighborhood SES adjusted for age and individual SES indices, which included family affluence scale (FAS), education level of parents, cohabitation with parents, and weekly allowance. Obesity OR was investigated according to neighborhood SES by FAS, and according to FAS by neighborhood SES.

Results: After adjusting for age and individual SES variables, there was no significant association between neighborhood SES and adolescent obesity for either boys or girls. However, girls in the high FAS group showed a pattern of lower neighborhood SES being associated with a significant increase in risk of obesity; in the high neighborhood SES group, boys showed a pattern of higher FAS being associated with a significant increase in risk of obesity, whereas girls show a pattern of decrease.

Conclusion: Although limited, the present study demonstrated that some girl groups exhibited a pattern of lower neighborhood SES being associated with an increase in risk of obesity, as well as a gender-based difference in risk of obesity by individual SES. Therefore, measures to prevent adolescent obesity should be established with consideration for differences in risk according to individual and neighborhood SES.
\end{abstract}

Keywords: Obesity; Neighborhood; Socioeconomic Status; Adolescent

Received: February 26, 2015, Revised: July 31, 2015, Accepted: September 24, 2015

*Corresponding Author: Da-jung Park Tel: +82-51-890-6729, Fax: +82-51-894-7554, E-mail: pdajung@ @anmail.net

*Corresponding Author: Jinseung Kim Tel: +82-51-890-6729, Fax: +82-51-894-7554, E-mail: jinseungkim@inje.ac.kr 


\section{INTRODUCTION}

With a rapid increase in prevalence worldwide, adolescent obesity is being recognized as an important health issue. ${ }^{1)}$ South Korea is also experiencing an increase in obese adolescents due to overnutrition and lack of physical activity. According to recently published reports by Statistics Korea and the Korea Ministry of Gender Equality \& Family, the prevalence of obesity in Korean adolescents was $15.3 \%$ in 2013, with boys (16.7\%) being $2.8 \%$ higher than girls (13.9\%); these numbers represented a $3.0 \%$ and $4.4 \%$ increase in prevalence of adolescent obesity in boys and girls, respectively, since 2006. ${ }^{2)}$

Adolescent Obesity can not only contribute to physical ailments that can occur during adolescence, such as hypertension, diabetes, and dyslipidemia, but can also lead to mental disorders, including eating disorders, depression, and suicide. ${ }^{3,4)}$ Moreover, adolescent obesity mostly leads to adult obesity, ${ }^{5)}$ causing various physical, mental, and social issues. ${ }^{6,7)}$ Thus, preventive prescreening and management of adolescents with a high risk of obesity are of utmost importance. ${ }^{8)}$

The causes of obesity include demographic, health behavior, and psychological factors, as well as environmental factors that include family, school, and community, and are associated with each other in a complex manner. ${ }^{9-12)}$ An individual's socioeconomic characteristics can lead to obesity since these are associated with health behaviors such as nutritional intake and physical activity. Moreover, a community possesses the physical and social traits that can influence an individual's health, and the socioeconomic characteristics of a region can influence the onset of obesity, since they are related to physical, cultural, and human infrastructure that can influence the health of individuals within that region. ${ }^{13)}$

Among prior studies that examined the influence of socioeconomic characteristics of a region on personal health, Stafford and Marmot approached the topic using two models. The first model was the collective resource model, which was based on the hypothesis that residents in affluent neighborhoods would have better health status than those in impoverished neighborhoods, since they had greater advantages in utilizing material and social resources (social support structure, community services, etc.). The second model was the local social inequality model, which was based on the hypothesis that a greater gap between the socioeconomic status (SES) of an individual and his or her neighborhood would indicate poorer health status of the individual. This study concluded that since the SES of a neighborhood has the trait of influencing the total available resources within the community, it can also influence the health of individuals.

However, most existing studies that analyzed the associations between socioeconomic characteristics of neighborhoods and obesity have limitations from using indicators that reflected only some of the characteristics, such as work, residence, and education. Moreover, there have been no studies in Korea that have used data representative of Korean adolescents. Thus, the present study aimed to examine the association between neighborhood SES and obesity in Korean adolescents using data from the 2013 Korea Youth Risk Behavior Web-based Survey (KYRBWS).

\section{METHODS}

\section{Subjects}

The present study used raw data from the 2013 KYRBWS, which was obtained from the homepage of KYRBWS after complying with the usage protocol of the Korea Centers for Disease Control and Prevention (KCDC) ${ }^{14)}$ The Korean version of the regional Deprivation Index (DI) from Health Promotion Strategies and Program Development for Health Inequalities Alleviation that was published in December 2009 by an academic cooperation foundation of Hanyang University was also used. ${ }^{15}$ )

KYRBWS is an anonymous online survey in a self-reporting format that Korea Health and Human Services, KCDC, and the Korea Ministry of Education, Science, and Technology have conducted annually since 2005 among middle and high school students in Korea to investigate health status. The survey was developed for sample schools according to city size, regional group, and school type among 16 major cities and provinces in Korea, and one sample class per grade level was randomly selected. All students in the sample classes were then surveyed on 126 questions in 15 categories, including smoking, drinking, physical activity, dietary habits, mental health, health equity, and others; the survey was conducted between June 1 and July 17, 2013 on 72,435 students from a total of 800 schools ( 400 middle and 400 high schools), and the response rate was $96.6 \%$, with 36,655 boys and 35,780 girls participating in the survey.

\section{Variable Measurements}

Self-reported height and weight were used to calculate body mass index (BMI, $\mathrm{kg} / \mathrm{m}^{2}$ ), and weight status was classified as percentile according to gender- and age-specific BMI on the 2007 Korea National Growth Chart for Children and Adolescents. The subjects were classified as underweight for $<5$ percentile, normal weight for $\geq 5$ to $<85$ percentile, overweight for $\geq 85$ to $<95$ percentile, and obese for $\geq 95$ percentile or BMI $\geq 25$.

The indicators used in estimating personal SES were family affluence scale (FAS), education level of parents, cohabitation with parents, and weekly allowance. FAS was classified into three groups of low-tier ( $0-2$ points), middle-tier (3-5 points), and high-tier (6-9 points), based on total score from questions and scores of: number of cars owned (none [0], one [1], and two or more [2]); have own room (no [0] and yes [1]); number 
of family weekend vacations during the past year (none [0], once [1], twice [2], and three or more times [3]); and number of household computers (none [0], one [1], two [2], and three or more [3]). Education level of parents was classified into three groups of middle school or less, high school graduation, and college or higher; cohabitation with parents was classified into four groups of no parents, father only, mother only, and both parents. Weekly allowance was classified as low-tier for 0-9,999 Korean won (KRW), middle-tier for 10,000-49,999 KRW, and high-tier for $\geq 50,000 \mathrm{KRW}$.

The Korean version of the neighborhood DI for area units of si- (city), gun- (county), and gu- (district) was classified into tertiles of low region (third tertile), middle region (second tertile), and high region (first tertile), which were used as indicators representing neighborhood SES. Neighborhood DI was an index derived from adding the standardized scores from a total of 8 subindices of DI that reflected neighborhood SES by using $2 \%$ of sample survey data from the 2005 population and housing survey, which the Korea Health Promotion Foundation used in Health Promotion Strategies and Program Development for Health Inequalities Alleviation. The index was calculated by adding the scores from rates of poor living environment, elderly population, population with education level below high school graduation, household members belonging to low social class, apartment households, single households, female-headed households, non-car-owning households (urban), and non-car-owning households (rural).

\section{Analysis}

IBM SPSS ver. 21.0 (IBM Co., Armonk, NY, USA) was used for statistical analysis, with statistical significance set to 0.05 . Data from KYRBWS were surveyed via systematic sampling and contained weighted values; hence, statistical analysis was performed by applying the weighted values. Differences in prevalence of obesity between males and females based on the subject's age, FAS, education level of parents, cohabitation with parents, weekly allowance, and neighborhood SES were analyzed using the chi-square test. For assessment of an independent association between adolescent obesity and neighborhood SES based on individual SES and a total available resource model, multivariate logistic regression analysis was performed with the first step adjusted for age (model 1), and the second step adjusted for age, FAS, education level of parents, cohabitation with parents, and weekly allowance (model 2).

For assessment of an independent association between adolescent obesity based on a local social inequality model and neighborhood SES, multivariate logistic regression analysis adjusted for age, education level of parents, cohabitation with parents, and weekly allowance was used to compare the obesity odds ratios (OR) according to neighborhood SES by FAS. To examine the combined influences of individual and neighbor- hood SES on adolescent obesity, multivariate logistic regression analysis was performed with the first step adjusted for age (model 1) and the second step adjusted for age, education level of parents, cohabitation with parents, and weekly allowance (model 2). For assessment of an independent association between individual SES and adolescent obesity that excluded the socioeconomic influences of the neighborhood, multivariate logistic regression analysis adjusted for age, education level of parents, cohabitation with parents, and weekly allowance was used to compare the obesity OR according to FAS by neighborhood SES.

\section{RESULTS}

\section{General Characteristics of Study Subjects}

The mean ages of boys and girls were $15.0 \pm 0.4$ and $14.9 \pm 0.4$ years, respectively, while mean BMI was $20.4 \pm \mathrm{SE} \mathrm{kg} / \mathrm{m}^{2}$ and $19.9 \pm \mathrm{SE} \mathrm{kg} / \mathrm{m}^{2}$, respectively. Prevalence of obesity was significantly higher in boys, at $13.1 \%$, versus $6.2 \%$ in girls (P-value $<0.001)$. FAS consisted of $11.3 \%$ in the low-tier, $51.7 \%$ in the middle-tier, and $37.0 \%$ in the high-tier, with a mean FAS score

Table 1. Prevalence of obesity according to individual and neighborhood SES in boys and girls

\begin{tabular}{|c|c|c|c|c|}
\hline \multirow[b]{2}{*}{ Variable } & \multicolumn{2}{|c|}{ Boys $(\mathrm{N}=35,575)$} & \multicolumn{2}{|c|}{ Girls $(N=34,779)$} \\
\hline & $\begin{array}{c}\%^{*} \\
\left(n=4,644^{\ddagger}\right)\end{array}$ & P-value ${ }^{\dagger}$ & $\begin{array}{c}\%^{*} \\
\left(n=2,271^{\ddagger}\right)\end{array}$ & P-value ${ }^{\dagger}$ \\
\hline Age (y) & & $<0.001^{\S}$ & & $<0.001^{\S}$ \\
\hline $12-15$ & 10.9 & & 5.3 & \\
\hline $16-18$ & 16.2 & & 7.4 & \\
\hline Family affluence scale & & 0.110 & & $<0.001^{\S}$ \\
\hline Low & 12.7 & & 8.8 & \\
\hline Middle & 13.5 & & 6.2 & \\
\hline High & 12.7 & & 5.4 & \\
\hline Allowance per week (Korean won) & & $0.001^{\S}$ & & 0.307 \\
\hline Low $(0-9,999)$ & 11.8 & & 6.1 & \\
\hline Middle (10,000-49,999) & 13.5 & & 6.1 & \\
\hline High $(\geq 50,000)$ & 14.6 & & 6.7 & \\
\hline Paternal education level & & $0.001^{\S}$ & & $<0.001^{\S}$ \\
\hline Middle school or less & 16.3 & & 9.9 & \\
\hline High school & 14.0 & & 7.5 & \\
\hline College or higher & 12.7 & & 4.7 & \\
\hline Maternal education level & & $0.001^{\S}$ & & $<0.001^{\S}$ \\
\hline Middle school or less & 16.3 & & 9.4 & \\
\hline High school & 14.2 & & 6.9 & \\
\hline College or higher & 12.6 & & 4.8 & \\
\hline Cohabitation with parents & & 0.001 & & $<0.001$ \\
\hline No parents & 12.4 & & 7.5 & \\
\hline Father only & 16.3 & & 7.3 & \\
\hline Mother only & 13.3 & & 8.7 & \\
\hline Both parents & 12.8 & & 5.9 & \\
\hline Neighborhood SES & & 0.530 & & $0.019^{\S}$ \\
\hline Low & 13.2 & & 6.7 & \\
\hline Middle & 12.8 & & 6.1 & \\
\hline High & 13.3 & & 5.7 & \\
\hline
\end{tabular}

SES, socioeconomic status.

${ }^{*}$ All the percentage is weighted percentage. ${ }^{\dagger}$ Estimated by the chi-squared test. ${ }^{*}$ The number of the obese adolescents. ${ }^{\S} \mathrm{P}$ for trend $<0.05$ estimated by likelihood ratio test for trend. 
of 4.8 points for both boys and girls. The most common education levels of parents were college or higher for fathers at $43.3 \%$ and high school graduation for mothers at $41.6 \%$. Living with both parents $(82.4 \%)$ was most common for cohabitation with parents, while the middle-tier (53.4\%) was the most common weekly allowance.

\section{Prevalence of Obesity according to Socioeconomic Variables of Individuals and Neighborhoods}

The differences in prevalence of obesity according to socioeconomic variables of individuals are shown in Table 1. Significant differences were seen according to education level of parents, cohabitation with parents, and weekly allowance in boys, and according to FAS, education level of parents, and cohabitation with parents in girls. In girls, lower FAS was associated with a significant increase in prevalence of obesity, while in boys and girls both, lower education level of parents was associated with a significant increase in prevalence. Prevalence of obesity according to cohabitation with parents was the highest in the groups that lived with only father or mother for boys and girls, respectively, while it was lowest in the groups that lived with no parent or both parents for boys and girls, respectively. In boys, more weekly allowance was associated with a significant increase in prevalence of obesity. Only girls showed a significant increase in prevalence of obesity according to lower neighborhood SES

\section{Obesity Odds Ratio according to Socioeconomic Variables of Individuals and Neighborhoods}

The obesity OR of boys and girls according to individual SES is shown in Table 2. Relative to the high FAS group, obesity OR of boys in the low FAS group was significantly low, with higher FAS tending to show a significant increase in OR; in girls, obesity OR in the low FAS group was significantly higher than that of the high FAS group. When paternal education levels were compared to the college or higher group, both boys and girls showed that lower education level resulted in a significant increase in obesity OR. For maternal education level, only girls tended to show lower education level resulting in a significant increase in OR. Obesity OR according to cohabitation with parents was significantly high in the groups that lived with father only for boys, and mother only for girls, relative to the group living with both parents. Meanwhile no significant differences in OR were seen in boys or girls for weekly allowance.

Obesity OR in boys and girls by neighborhood SES based on a total available resource model is shown in Table 2. Obesity OR was significantly higher in girls from the low-tier neighborhood group than in the high-tier neighborhood group, while boys did not show any significant difference. The effects of nei-

Table 2. Adjusted ORs for obesity according to individual and neighborhood SES in boys and girls

\begin{tabular}{|c|c|c|c|c|}
\hline \multirow{2}{*}{ Variable } & \multicolumn{2}{|c|}{ Boys } & \multicolumn{2}{|c|}{ Girls } \\
\hline & Model $1^{*}$ & Model $2^{\dagger}$ & Model $1^{*}$ & Model $2^{\dagger}$ \\
\hline \multicolumn{5}{|l|}{ FAS } \\
\hline Low & $0.92(0.83-1.02)$ & $0.76(0.66-0.88)$ & 1.59 (1.39-1.82) & $1.22(1.02-1.45)$ \\
\hline Middle & $0.98(0.92-1.05)$ & $0.95(0.88-1.00)$ & $1.10(1.00-1.20)$ & $1.00(0.90-1.12)$ \\
\hline High & 1 (Reference) & 1 (Reference) $^{\ddagger}$ & 1 (Reference) $^{\ddagger}$ & 1 (Reference) \\
\hline \multicolumn{5}{|c|}{ Allowance per week (Korean won) } \\
\hline Low $(0-9,999)$ & 1 (Reference) & 1 (Reference) & 1 (Reference) & 1 (Reference) \\
\hline Middle $(10,000-49,999)$ & $1.04(0.96-1.11)$ & $1.03(0.95-1.13)$ & $0.91(0.83-1.00)$ & $0.90(0.79-1.02)$ \\
\hline High $(\geq 50,000)$ & $1.03(0.93-1.14)$ & $1.02(0.90-1.15)$ & $0.92(0.80-1.05)$ & $0.91(0.73-1.06)$ \\
\hline \multicolumn{5}{|l|}{ Paternal education level } \\
\hline Middle school or less & $1.24(1.05-1.46)$ & $1.21(1.00-1.47)$ & $2.08(1.71-2.54)$ & $1.71(1.33-2.18)$ \\
\hline High school graduation & $1.08(0.99-1.16)$ & $1.07(0.98-1.18)$ & $1.59(1.44-1.76)$ & $1.42(1.26-1.59)$ \\
\hline College or higher & 1 (Reference) $^{\ddagger}$ & 1 (Reference) $^{\ddagger}$ & 1 (Reference) $^{\ddagger}$ & 1 (Reference) $^{\ddagger}$ \\
\hline \multicolumn{5}{|l|}{ Maternal education level } \\
\hline Middle school or less & $1.20(1.01-1.43)$ & $1.17(0.96-1.43)$ & $1.90(1.52-2.37)$ & $1.28(0.99-1.67)$ \\
\hline High school & $1.08(1.06-1.15)$ & $1.06(0.98-1.14)$ & $1.42(1.28-1.57)$ & $1.21(1.07-1.36)$ \\
\hline College or higher & 1 (Reference) $^{\ddagger}$ & 1 (Reference) & 1 (Reference) $^{\ddagger}$ & 1 (Reference) $)^{\star, \neq}$ \\
\hline \multicolumn{5}{|l|}{ Cohabitation with parents } \\
\hline No parents & $0.92(0.75-1.11)$ & $0.95(0.69-1.31)$ & $1.24(0.97-1.59)$ & $1.38(0.95-2.01)$ \\
\hline Father only & $1.27(1.16-1.41)$ & $1.32(1.15-1.52)$ & $1.22(1.07-1.40)$ & $1.14(0.94-1.40)$ \\
\hline Mother only & $1.02(0.89-1.18)$ & $1.27(1.00-1.61)$ & $1.50(1.23-1.84)$ & $1.55(1.17-2.05)$ \\
\hline Both parents & 1 (Reference) & 1 (Reference) & 1 (Reference) & 1 (Reference) \\
\hline \multicolumn{5}{|l|}{ Neighborhood SES } \\
\hline Low & $0.98(0.91-1.07)$ & 0.99 (0.89-1.09) & $1.19(1.06-1.35)$ & $1.14(1.00-1.30)$ \\
\hline Middle & $0.96(0.88-1.04)$ & $0.96(0.87-1.06)$ & 1.07 (0.95-1.21) & $1.20(0.96-1.25)$ \\
\hline High & 1 (Reference) & 1 (Reference) & 1 (Reference) $^{\ddagger}$ & 1 (Reference) \\
\hline
\end{tabular}

Values are presented as ORs (95\% Cl). ORs and 95\% Cls were estimated with multivariate logistic regression analysis.

$\mathrm{OR}$, odds ratio; SES, socioeconomic status; FAS, family affluence scale; $\mathrm{Cl}$, confidence interval.

${ }^{*}$ Adjusted for age. ${ }^{\dagger}$ Adjusted for age, FAS, paternal education level, maternal education level, cohabitation with parents, allowance per week, and neighborhood SES. ${ }^{\text {tP-for }}$ trend $<0.05$ estimated by likelihood ratio test for trend. 
Table 3. Adjusted ORs for obesity according to neighborhood SES among FAS in boys and girls

\begin{tabular}{lccc}
\hline FAS & Neighborhood SES & Boys & Girls \\
\hline Low & Low & $0.98(0.89-1.09)$ & $1.41(1.10-1.30)$ \\
& Middle & $0.96(0.87-1.06)$ & $1.10(0.96-1.25)$ \\
\multirow{3}{*}{ Middle } & High & 1 (Reference) & 1 (Reference) \\
& Low & $0.93(0.82-1.06)$ & $1.02(0.86-1.21)$ \\
& Middle & $0.94(0.84-1.06)$ & $1.02(0.85-1.21)$ \\
High & High & 1 (Reference) & 1 (Reference) \\
& Low & $1.04(0.91-1.19)$ & $1.39(1.12-1.73)$ \\
& Middle & $0.91(0.79-1.04)$ & 1.24 (0.99-1.54) \\
& High & 1 (Reference) & 1 (Reference) \\
\hline
\end{tabular}

Values are presented as ORs $(95 \% \mathrm{Cl})$. ORs and 95\% Cls were estimated with multivariate logistic regression analysis adjusted for age, paternal education level, maternal education level, cohabitation with parents and allowance per week.

$\mathrm{OR}$, odds ratio; SES, socioeconomic status; FAS, family affluence scale; $\mathrm{Cl}$, confidence interval.

*P-for trend $<0.05$ estimated by likelihood ratio test for trend.

ghborhood SES on obesity based on the local social inequality model are shown in Table 3. Boys showed no significant difference in obesity OR according to neighborhood SES by FAS, while girls exhibited a pattern of significant increase in obesity OR with lower neighborhood SES in the high-tier FAS group, as well as an increase in obesity OR, although not significant, with lower neighborhood SES in the low-tier FAS group.

The influence of individual SES on adolescent obesity with exclusion of socioeconomic influences of the neighborhood is shown in Table 4. Boys exhibited a pattern of higher FAS being associated with a significant increase in obesity OR in the high and low neighborhood SES groups, whereas girls tended to show higher FAS being associated with a decrease in obesity OR in the high neighborhood SES group.

\section{DISCUSSION}

The present study used the data from the 2013 KYRBWS in examining the influences of socioeconomic factors on adolescent obesity at both individual and neighborhood levels. In both boys and girls, neighborhood SES did not significantly influence obesity, but girls did exhibit a pattern of lower neighborhood SES being associated with a significant increase in risk of obesity in the high FAS group. The association between individual SES and adolescent obesity showed a pattern of genderbased differences; boys in high SES neighborhoods showed higher FAS being associated with a significant increase in risk of obesity, whereas girls showed higher FAS being associated with a significant decrease in risk of obesity.

In a review of prior studies analyzing the association between regional socioeconomic characteristics and obesity in adolescents, a study on Canadian adolescents found that for lower neighborhood SES, that took into consideration local unemployment rate and population, a rate of education level below middle school was associated with an increase in consumption
Table 4. Adjusted ORs for obesity according to FAS among neighborhood SES in boys and girls

\begin{tabular}{llrr}
\hline Neighborhood SES & \multicolumn{1}{c}{ FAS } & \multicolumn{1}{c}{ Boys } & \multicolumn{1}{c}{ Girls } \\
\hline Low & Low & $0.72(0.57-0.91)$ & $1.06(0.80-1.42)$ \\
& Middle & $0.88(0.78-0.99)$ & $0.88(0.74-1.05)$ \\
\multirow{3}{*}{ Middle } & High & 1 (Reference) $^{*}$ & 1 (Reference) \\
& Low & $0.99(0.78-1.26)$ & $1.15(0.86-1.54)$ \\
& Middle & $0.98(0.88-1.09)$ & $0.96(0.80-1.15)$ \\
High & High & 1 (Reference) & 1 (Reference) \\
& Low & $0.59(0.45-0.76)$ & $1.50(1.06-2.13)$ \\
& Middle & $0.96(0.85-1.09)$ & $1.23(0.99-1.51)$ \\
& High & 1 (Reference) $^{*}$ & 1 (Reference) $^{*}$ \\
\hline
\end{tabular}

Values are presented as ORs $(95 \% \mathrm{Cl})$. ORs and $95 \%$ Cls were estimated with multivariate logistic regression analysis adjusted for age, paternal education level, maternal education level, cohabitation with parents and allowance per week.

$\mathrm{OR}$, odds ratio; $\mathrm{SES}$, socioeconomic status; $\mathrm{FAS}$, family affluence scale; $\mathrm{Cl}$, confidence interval.

*P-for trend $<0.05$ estimated by likelihood ratio test for trend.

of unhealthy foods, and lower individual SES was associated with decreased physical activities; hence, the study reported that individual and regional SES was directly associated with adolescent obesity. ${ }^{16)}$ A study on American adolescents reported that in addition to individual characteristics, such as monthly household income, a lower regional SES based on poverty rate and physical surroundings was significantly associated with an increase in obesity in children and adolescents. ${ }^{17)}$ Another study on American adolescents found that having decreased access to service resources within the community, such as walkways, playgrounds, recreational spaces, and welfare facilities, resulted in an increase in obesity rate. ${ }^{18)}$ Yet another study from America reported that when adolescent obesity rate was investigated according to distribution of neighborhood sports facilities, an increase in social capital within a neighborhood increased the number of available sports facilities, which in turn decreased the adolescent obesity rate. ${ }^{19)}$

Although many studies have reported that individual and neighborhood SES is closely associated with adolescent obesity, the present study did not find a clear-cut association. However, girls in the high FAS group did show a pattern of significantly increased risk of obesity in association with lower neighborhood SES. This demonstrated, in a limited manner, that the association between neighborhood SES and adolescent obesity was based on the total available resources model, which hypothesizes that accessibility of physical and social resources within the community of residence influences the health of individuals; this is in contrast to the local social inequality model, which hypothesizes that relative deprivation due to differences in the levels of individual SES, and socioeconomic level of the neighborhood that the individual resides in, influence the individual's health. In other words, higher neighborhood SES means having a more abundant supply of physical and social resources within the community that are needed for prevention and management of obesity; hence, the risk of obesity would de- 
crease due to more favorable conditions for utilizing such resources.

Relationships between individual SES and obesity based on gender showed patterns that differed from each other. These patterns also appear in adults, with numerous studies reporting that obesity in men was associated with income, but in women was associated with education level. ${ }^{20-25)}$ The reason that risk of obesity according to individual SES differs by gender is believed to be due to gender-based differences in awareness of and satisfaction with body type. ${ }^{26)}$ With advances in society, awareness of obesity has also increased; due to the sociocultural influence of preference for thin body types, interest in weight control increases as well. However, women more than men are sensitive to outer appearance or body type; since there is a tendency for obesity in women to act as a disadvantage in the market economy, women show a strong tendency to prefer a thin body type compared to men. Moreover, women often attempt to control their weight, since their interest in body type is higher when SES factors such as income and education level are higher; they become dissatisfied with their body type as a result of being overly conscious of it. Because of this, a significant decrease in the risk of obesity may have been seen in girls with higher FAS. ${ }^{20,27-29)}$ In contrast, men are freer than women from social pressures related to body type, ${ }^{30)}$ and tend to take on a somewhat cynical attitude toward taking measures to prevent obesity and improve health. ${ }^{31)}$ Moreover, because of psychological characteristics that view a larger body as physically superior to a thin body type, ${ }^{20)}$ men are believed to show results that differ from women.

The significance of the present study is that it used data from Korea that were representative of the entire nation; it also used the Korean version of the neighborhood DI, which is an index that comprehensively assesses neighborhood SES, in identifying relative differences within the community; furthermore, it analyzed the independent influences of neighborhood SES on adolescent obesity by controlling for various individual indices. However, the Korean version of the neighborhood DI used to estimate SES was derived from a $2 \%$ sample of survey data from a 2005 population and housing survey; thus, the study has the limitation associated with use of a sample rather than a full enumeration survey. Moreover, because the regional units analyzed in the Korean version neighborhood DI and 2013 KYRBWS were not the same, there are limitations in making an accurate estimation of neighborhood SES. Furthermore, because KYRBWS was conducted in a self-reporting format, inaccurate data may have been entered through failing to realize that the numbers had changed, which can present limitations in interpretation of the results. ${ }^{32)}$ The present study applied conventional single-level analysis to multilevel data that combined individual level variables with regional level variables. This presents limitations in the interpretation of the results, since ana- lyzing multilevel data at an individual level cannot satisfy the independence of observation assumption; in contrast, analysis at a regional level can cause contextual and ecological fallacies, since individual level variables are aggregated for use. Therefore, for more in-depth analysis on how individual and neighborhood SES influences obesity, future studies that use multilevel model analysis are needed.

Although limited to only some groups of girls, the present study did identify a pattern of lower neighborhood SES leading to an increase in risk of obesity, and also confirmed a genderbased difference in risk of obesity according to individual SES. Therefore, in establishing measures for prevention and management of adolescent obesity, it is necessary to reinforce individualized support in high SES regions, and strengthen the physical, cultural, and human infrastructure within the community in low SES regions. It is equally necessary to devise educational and policy measures aimed at boys in high individual SES groups and girls in low SES groups.

\section{CONFLICT OF INTEREST}

No potential conflict of interest relevant to this article was reported.

\section{REFERENCES}

1. Jeong BG, Moon OR, Kim NS, Kang JH, Yoon TH, Lee SY, et al. Socioeconomic costs of obesity for Korean adults. Korean J Prev Med 2002; 35:1-12.

2. Statistics Korea. 2014 Statistics of adolescents in Korea [Internet]. Daejeon: Statistics Korea; 2014 [cited 2014 Jul 10]. Available from: http:// kostat.go.kr.

3. Weiss R, Dziura J, Burgert TS, Tamborlane WV, Taksali SE, Yeckel CW, et al. Obesity and the metabolic syndrome in children and adolescents. N Engl J Med 2004;350:2362-74.

4. McElroy SL, Kotwal R, Malhotra S, Nelson EB, Keck PE, Nemeroff CB. Are mood disorders and obesity related? A review for the mental health professional. J Clin Psychiatry 2004;65:634-51.

5. Togashi K, Masuda H, Rankinen T, Tanaka S, Bouchard C, Kamiya H. A 12-year follow-up study of treated obese children in Japan. Int J Obes Relat Metab Disord 2002;26:770-7.

6. Adami F, Vasconcelos Fde A. Childhood and adolescent obesity and adult mortality: a systematic review of cohort studies. Cad Saude Publica 2008;24 Suppl 4:s558-68.

7. Adams KF, Schatzkin A, Harris TB, Kipnis V, Mouw T, Ballard-Barbash $\mathrm{R}$, et al. Overweight, obesity, and mortality in a large prospective cohort of persons 50 to 71 years old. N Engl J Med 2006;355:763-78.

8. Goldschmidt AB, Wilfley DE, Paluch RA, Roemmich JN, Epstein LH. Indicated prevention of adult obesity: how much weight change is necessary for normalization of weight status in children? JAMA Pediatr 2013;167:21-6.

9. Lioret S, Maire B, Volatier JL, Charles MA. Child overweight in France and its relationship with physical activity, sedentary behaviour and so- 
cioeconomic status. Eur J Clin Nutr 2007;61:509-16.

10. Krebs NF, Himes JH, Jacobson D, Nicklas TA, Guilday P, Styne D. Assessment of child and adolescent overweight and obesity. Pediatrics 2007;120 Suppl 4:S193-228.

11. Romao I, Roth J. Genetic and environmental interactions in obesity and type 2 diabetes. J Am Diet Assoc 2008;108(4 Suppl 1):S24-8.

12. Marmot MG. Socio-economic factors in cardiovascular disease. J Hypertens Suppl 1996;14:S201-5.

13. Stafford M, Marmot M. Neighbourhood deprivation and health: does it affect us all equally? Int J Epidemiol 2003;32:357-66.

14. Korea Centers for Disease Control and Prevention. 2013 Korean Youth's Risk Behavior Web-based Survey (KYRBWS) [Internet]. Cheongju: Korea Centers for Disease Control and Prevention; 2013 [cited 2014 Dec 13]. Available from: http://yhs.cdc.go.kr.

15. Shin Y, Yoon T, Kim M, Cho H, Kim M, Yoo W, et al. Health promotion strategies and programmes development for health inequalities alleviation. Seoul: Cooperative System of Hanyang University \& Management Center for Health Promotion; 2009.

16. Janssen I, Boyce WF, Simpson K, Pickett W. Influence of individual- and area-level measures of socioeconomic status on obesity, unhealthy eating, and physical inactivity in Canadian adolescents. Am J Clin Nutr 2006;83:139-45.

17. Singh GK, Kogan MD, van Dyck PC. A multilevel analysis of state and regional disparities in childhood and adolescent obesity in the United States. J Community Health 2008;33:90-102.

18. Singh GK, Siahpush M, Kogan MD. Neighborhood socioeconomic conditions, built environments, and childhood obesity. Health Aff (Millwood) 2010;29:503-12.

19. Gordon-Larsen P, Nelson MC, Page P, Popkin BM. Inequality in the built environment underlies key health disparities in physical activity and obesity. Pediatrics 2006;117:417-24.

20. Wardle J, Waller J, Jarvis MJ. Sex differences in the association of socio- economic status with obesity. Am J Public Health 2002;92:1299-304.

21. Paeratakul S, Lovejoy JC, Ryan DH, Bray GA. The relation of gender, race and socioeconomic status to obesity and obesity comorbidities in a sample of US adults. Int J Obes Relat Metab Disord 2002;26:1205-10.

22. Wamala SP, Wolk A, Orth-Gomer K. Determinants of obesity in relation to socioeconomic status among middle-aged Swedish women. Prev Med 1997;26(5 Pt 1):734-44.

23. Rissanen AM, Heliovaara M, Knekt P, Reunanen A, Aromaa A. Determinants of weight gain and overweight in adult Finns. Eur J Clin Nutr 1991;45:419-30.

24. Woo J, Leung SS, Ho SC, Sham A, Lam TH, Janus ED. Influence of educational level and marital status on dietary intake, obesity and other cardiovascular risk factors in a Hong Kong Chinese population. Eur J Clin Nutr 1999;53:461-7.

25. Wen W, Gao YT, Shu XO, Yang G, Li HL, Jin F, et al. Sociodemographic, behavioral, and reproductive factors associated with weight gain in Chinese women. Int J Obes Relat Metab Disord 2003;27:933-40.

26. Sobal J, Stunkard AJ. Socioeconomic status and obesity: a review of the literature. Psychol Bull 1989;105:260-75.

27. Wardle J, Griffith J. Socioeconomic status and weight control practices in British adults. J Epidemiol Community Health 2001;55:185-90.

28. García Villar J, Quintana-Domeque C. Income and body mass index in Europe. Econ Hum Biol 2009;7:73-83.

29. Wardle J, Parmenter K, Waller J. Nutrition knowledge and food intake. Appetite 2000;34:269-75.

30. Rolls BJ, Fedoroff IC, Guthrie JF. Gender differences in eating behavior and body weight regulation. Health Psychol 1991;10:133-42.

31. Gough B, Conner MT. Barriers to healthy eating amongst men: a qualitative analysis. Soc Sci Med 2006;62:387-95.

32. Song YM, Yoon JL. The accuracy of self-reported weight and height. Korean J Epidemiol 1995;17:257-68. 